\title{
Paula Abramo.
}

\section{Fiat Lux. México:}

\section{Editorial Tierra}

Adentro, 2012.

\section{Paulo Moreira}

Paulo Moreira nació en Rio de Janeiro en 1969 y creció en Belo Horizonte, Minas Gerais. Graduado en Letras Inglesas por la Universidad Federal de Minas Gerais, hizo su doctorado en Literatura Comparada en la Universidad de California en Santa Bárbara. Paulo Moreira es profesor asociado del departamento de español y portugués de la Universidad de Yale en Estados Unidos desde 2006. Sus áreas de interés principales son las literaturas brasileña, mexicana y estadounidense del siglo XX; la narrativa moderna; el cinema latinoamericano contemporáneo, el cuento y la poesía. Ha publicado artículos sobre autores mexicanos, brasileños y americanos; literatura afro-brasileña y cinema contemporáneo en Brasil, Estados Unidos, Inglaterra y España. Su primer libro, Localismo Modernista nas Américas: Os contos de Faulkner, Guimarães Rosa e Rulfo, fue publicado en Brasil por la Editorial UFMG. El segundo libro, Literary and Cultural Relations Between Braqil and Mexico: Deep Undercurrents, salió en diciembre de 2013 por Palgrave Macmillan.

Contacto: paulo.moreira@yale.edu 
Um dos melhores livros de poesia brasileira que li nos últimos tempos foi escrito em espanhol por uma mexicana. Paula Abramo (1980) publicou Fiat Lux(2012) no México, onde o livro foi muito bem recebido: considerado um dos melhoresde 2012 pela revista de arte La Tempestad (que afirmou que "en la escritura de Fiat Lux se confirma una buena noticia: la apertura de la poesía mexicana a otros cauces, luego de años de empantanamiento") e ganhador em 2013 do prêmio Joaquín Xirau Icaza. Na cerimônia de entrega do prêmio Elsa Cross descreveu Fiat Lux como

uno de los mejores poemarios publicados por jóvenes en los últimos años, cuy a sustancia radica en ser una poesía sumamente depurada, en la que la autora toca las cosas más concretas sin ser prosaica, enlazando referencias clásicas y facturas poéticas muy nuevas, que muestra erudición en muchos temas y despliega con soltura una enorme variedad de recursos expresivos (Milenio, March 21, 2013).

Mas o que é que tudo isso tem a ver com a poesia brasileira? Paula é neta de Fúlvio Abramo (1909-1993), militante trotskista que liderou a Frente Única Antifascista[FUA] numa batalha campal épica na Praça da Sécontra 6,000 integralistas. Fúlvio foi preso pelo regime Vargas em 1935 por ter supostamente participado na intentona comunista e, quando deixou a prisão depois de um ano e meio para aguardar em liberdade pelo seu julgamento, preferiu fugir para a Bolivia, onde viveu por dez anos dando aulas na escola de agricultura e veterinária de Santa Cruz de la Sierra. Na volta ao Brasil Fúlvio empenhou-se novamente na vida política do país, tendo sido um dos fundadores do Partido dos Trabalhadores em 1980.

Fúlvio e seus irmãos deixaram sua marca na cultura brasileira ${ }^{1}$. São eles o artista (depois naturalizado Paraguaio) Lívio Abramo (1903-1992),

1 Há que se destacar ainda o filho de Athos Abramo, o jornalista e militante socialista Perseu Abramo (1929-1996) e o filho de Claudio Abramo, Cláudio Weber Abramo, fundador e presidente da ONG Transparência Brasil. 
o crítico e diretor de teatro Athos Abramo (1905-1968), a atriz e militante Lélia Abramo (1911-2004) eo jornalista Cláudio Abramo (1923-1987). São filhos de dois imigrantes italianos, Vincenzo Abramo (1869-1949) e Afra Yole Scarmagnan (1882-1966), criados entre a sofisticada biblioteca do pai e as raízes libertárias da mãe-Yole era filha de Bortolo Scarmagnan (1848-1932), padeiro italiano especialista em panettones e amaretti e veterano de lutas anarquistas. Os Abramos estenderam um ramo da família até o México quando um dos filhos de Fúlvio, o antropólogo brasileiro Marcelo Abramo Lauff, imigrou fugindo do regime militar e fixou-se permanentemente naquele país.

Nada disso faria de Fiat Lux um livro brasileiro, não fosse o fato de que nele Paula Abramo ter transformado em matéria poética a história da sua família, vivida entre Itália, México e principalmente o Brasil. Há fontes em prosa para muitasdas histórias - não todas - contidas em Fiat Lux: as memórias de Lélia Abramo Vida e Arte [1997] e os testemunhos de Lélia e Fulvio à revista Teoria e Debate e coletados em Rememória--Entrevistas sobre o Brasil do Século XX in 1997 (11-27, 63-82). Fiat Lux não pode ser substituído por nenhum desses testemunhos simplesmente porque é um animal literário de outra espécie: passa longe de ser uma série indulgente de memórias ligadas por vagas referências ao organizar-se num todo de arquitetura rigorosa com grande qualidade narrativa e altíssima voltagem poética.

Fiat Lux significativamente interrompe a sua linha narrativa no momento do exílio do pai de Paula Abramo. Dessa forma o livro lembra a calculada escrita que passeia pela vida dos ancestrais sem chegar a vida do próprio narrador que mesmo assim insiste em ser o dono de Life and Opinions of Tristram Shandy de Lawrence Sterne. Em Fiat Lux a voz poética retorna de tempos em tempos ao conselho de seu avô, contido em uma de suas cartas do exílio na Bolívia: "No mires hacia dentro." Dessa maneira Fiat Luxé um livro profundamente pessoal que sabe evitar exemplarmente a tendência ao excessivo auto-centramento da lírica no século XX e ao 
exibicionismo confessional do século XXI. A força emocional do livro de Paula Abramoestá na força das figuras que emergem e voltam à vida nas suas páginas: o anarquista Bôrtolo Scarmagnan, o veterano do exército vermelho Rudolf Josip Lauff, a operária da fábrica de fósforos Anna Stefania Lauff e seu marido militante antifascista Fúlvio. Essas figuras saídas das memórias familiares para renascer nos versos de Fiat Luxnão são heróicas no sentido épico do termo, mas porquevivem plenamente no seu desejo de viver e sonhar um mundo melhor que é mais importante que os eventuais triunfos e derrotas.

De onde vêm a força e vitalidade literária desses personagens e de suas histórias? De um texto poético de altíssima qualidade na sua atenção minuciosa aos detalhes, na exploração das possibilidades da linguagem e na voz poética original que explora o lirismo sem apoiar-se nas convenções de tom e dicção "elevados", Paula Abramo constrói uma voz poética que não é fria mas que não tem medo de ser objetiva e lançar um olhar atento à superfície das coisas e além disso é capaz de um tipo de raciocínio por analogia sustentada na melhor tradição de João Cabral de Melo Neto, poetaque Paula Abramo traduziu para o espanhol. A poeta de Fiat Lux não tem medo de palavras "difíceis," explorando os recantos menos visitados do léxico sem ostentar qualquer ranço de pretensão erudita. Esse é um conjunto de escolhas felizes que permite Paula Abramo já no seu primeiro livro a tirar o melhor do seu temperamento poético. Fiat Luxt em também um sentido de urgência incomum numa época em que escreve-se e publica-se muito sem uma visão aguda das necessidades e questões do mundo complicado que habitamos. O reavivamento dos mortos no livro de Paula Abramo não é resultado de nostalgia ou melancolia, mas da celebração enfática da vontade de continuar a viver e lutar.

De todos esses personagens extraordinários, construídos com a matéria bruta da memória da família, destaco Angelina, figura que abre e fecha Fiat Lux. Angelina é o único personagem sem sobrenome, indicação possível 
de que ela esteja mais próxima do ficcional do que os outros personagens. A ela é dado um contexto menos claramente definido no tempo e no espaço, mas isso não a faz menos vital que os outros. É de Angelina o primeiro fiat lux do livro,o acender de um fósforo que se torna um motivo de consistência admirável no livro como um todo. Angelina acende esse primeiro fósforo após um comando no imperativo, esse "pobre modo" cuja "falta essencial" é sua relativa impersonalidade-Angelina é uma empregada que recebe a ordem, presumivelmente de um patrão invisível, para fritar camarões numa cozinha que é "casi pasillo" (11). Como a voz poética de Fiat Lux, Angelina carrega consigo o peso da história, no caso da personagem do passado de humilde nordestina, de migrações forçadas, de seca e da "hambre de su abuela" (11). Nesse livro de fantasmas tão vívidos Angelina aparece ainda mais viva para afirmar a continuação no presente da fome, "ese fantoche de mal gusto" (75), e de "una riqueza enorme y mal distribuida / de crustáceos en el mundo, y de libros y de tiempo / para leerlos" (75). Mas além dessas continuidades sofridas, Angelina também reafirma a possibilidade da desobediência "en la frontera minúscula que media / entre la orden y el hecho de cumprirla" (76), subvertendo aquele fiat lux imposto ao comer "tres a cada cuatro" dos camarões que frita. Angelina, que é "breve y es ficticia" (75), é uma presença marcante que abre e fecha o livro de Paula Abramo reafirmando aquela que era a grande paixão de Fúlvio e de muitos outros Abramos: a luta pelo direito de escolher "por el acato o el desacato" (76) e de tomar posse dos frutos do próprio trabalho.

O título do livro e a série de reflexões sobre o gesto que ele indica são exemplos da rica textura dos versos de Paula Abramo, versos embebidos na herança clássica de uma escritora que se graduou pela UNAM justamente nesse campo de estudos. O Fiat Lux do título incorpora essa combinação instigante de vitalidade urgente, história, memória familiar e erudição: Fiat Lux é, ao mesmo tempo, o comando bíblico que coloca em movimento a história do mundo na versão latina do Genesis e a marca impressa milhões 
de caixas de fósforos no Brasil, os fósforos que aparecem e reaparecem em cada um dos poemas do livro, passando pelas mãos dessas duas mulheres inesquecíveis: Anna Stefania Lauff, a operária da fábrica de fósforos e Angelina, a empregada que os consome na cozinha onde trabalha.

Além da formação clássica, Paula Abramo ensina literatura brasileira na UNAM e já traduziu um número impressionante de obras brasileiras de autores como Ferreira Gullar, João Cabral de Melo Neto e Raul Pompéia. Sua ligação com o Brasil é profunda e Fiat Lux comprova essa consistência tão rara. Paula Abramo pertence a uma geração de escritoras menos afeitas a seguir as velhas rotas que ligam cada um dos países latino-americanos antes de tudo aos Estados Unidos, aos seus antigos colonizadores e à Europa ocidental. Tenho o prazer de dizer que, pela primeira vez desde o Poemas de Río de Enero de Alfonso Reyes, um dos melhores livros de poesia brasileira foi escrito em espanhol. 